\title{
Lo de abajo es lo que se muestra. "La piel sobre la que vivimos", un poema de Mustafa Stitou
}

What lies beneath is what is shown. "De schil waarop wij leven", a poem by Mustafa Stitou

\section{Alejandra Szir}

Universidad de Leiden, Países Bajos

El poema de Mustafa Stitou (Tetuán, 1974) que vamos a analizar es emblemático para la poesía en lengua neerlandesa de los últimos años. Lo reproduciré en forma integral y a continuación adjuntaré una traducción que he hecho para facilitar el análisis. Luego daré información imprescindible respecto al contexto y la recepción. Finalmente pasaré a interpretarlo para mostrar la relevancia de su poética, que se extiende más allá del ámbito de los estudios literarios neerlandeses y se involucra políticamente con el mundo actual, atravesando diferencias culturales. Además de servirme de El desacuerdo (Jacques Rancière, 1996), como referencia ineludible, me apoyé en la teoría de práctica política feminista de Chela Sandoval (2004), ya que, en mi opinión, su concepto de amor es un elemento fundamental en el tipo de compromiso que ensaya la poesía de Stitou.

Para empezar reproduzco el poema (Stitou, 2003a:26-29) e, inmediatamente debajo, la traducción. Respecto a esta versión en español, y a fragmentos traducidos en este artículo, quiero aclarar que he optado por la variedad rioplatense, por serme la más cercana, en los casos en que el léxico original resulta coloquial o banal. Más justificaciones podrán encontrarse en el transcurso del análisis.

\section{De schil waarop wij leven}

1

Het onderliggende het zich tonende, het zich tonende het zich tonende. Op voormalige zeebodem een vinexvesting, met zo natuurlijk

mogelijk bos omgeven, recreatiepaden, en met kunstwerk binnenkort. Alma Mater heet het beeld van Johan IJzerman

en wordt gebouwd van gras, de schil waarop wij leven.

Hier zijn pionieren klootjes of crimineel 
en wie niet te categoriseren valt

in een aparte doos - woonkamers wemelen

van geruchten over een pedofiele buur

en asielkampen moeten het liefst

aan de horizon staan, zo scheidt men

het goede van het zwarte.

Transcendentie schenkt een machtige eik misschien, een afgewaaid takje staat goed in een vaas

chrysanten, weet Klazien.

Eindelijk een eigen winkelstraat! Er staat al snackbar Zeemansgraf. Een Albert Heijn.

En waar het bordje dus niet brommen hangt

is een kroeg beloofd. Tegen ratten

wordt gewaarschuwd. Het asfalt

plakt, er staat

in de winkelstraat

een brommer

in brand.

Het onderliggende

het zich tonende, het zich tonende

het zich tonende.

3

De snackbarhouder heeft aura.

Trekt automatisch klanten aan.

Schenkt twee uitgeprocedeerde

Somalische Lolita's knipogend

softijs. Een stratenmaker vreet en vreet

wanneer hij schichtig opkijkt blozend.

Lokaal nieuws brengt een trotse agent: 'het ex-vriendje van het stoffelijk overschot heeft bekend.'

Een stokoud stelletje aan een paars plastic tafeltje,

Frits met zijn grotesk gezellig hoofd, schepper van vlinders van hout, en Wilma hobbyboerin in een vorig leven slurpt iets beuzelt 'Frits,

Frits, wat ik je vergeten was vannacht toen ik plassen moest zag ik

in dat rare maanlicht vind je niet?

Een joekel van een hert in ons tuintje het beest dronk op z'n dooie gemak ons vijvertje zowat op Frits...' 
4

Mooi weer moet worden benut. Oneindigheid.

Het onderliggende is het zich tonende,

het zich tonende het zich tonende.

Wilma en Frits, in een eeuwig heden

wachtend op de bus richting

Bachmeezingzomermiddag.

Oneindigheid het zich tonende.

Mooi weer het zich tonende.

Het onderliggende het zich tonende.

En als de wiedeweerga weer

naar huis: lieve ouwe rotte poes

ligt nog altijd op sterven.

\section{La piel sobre la que vivimos}

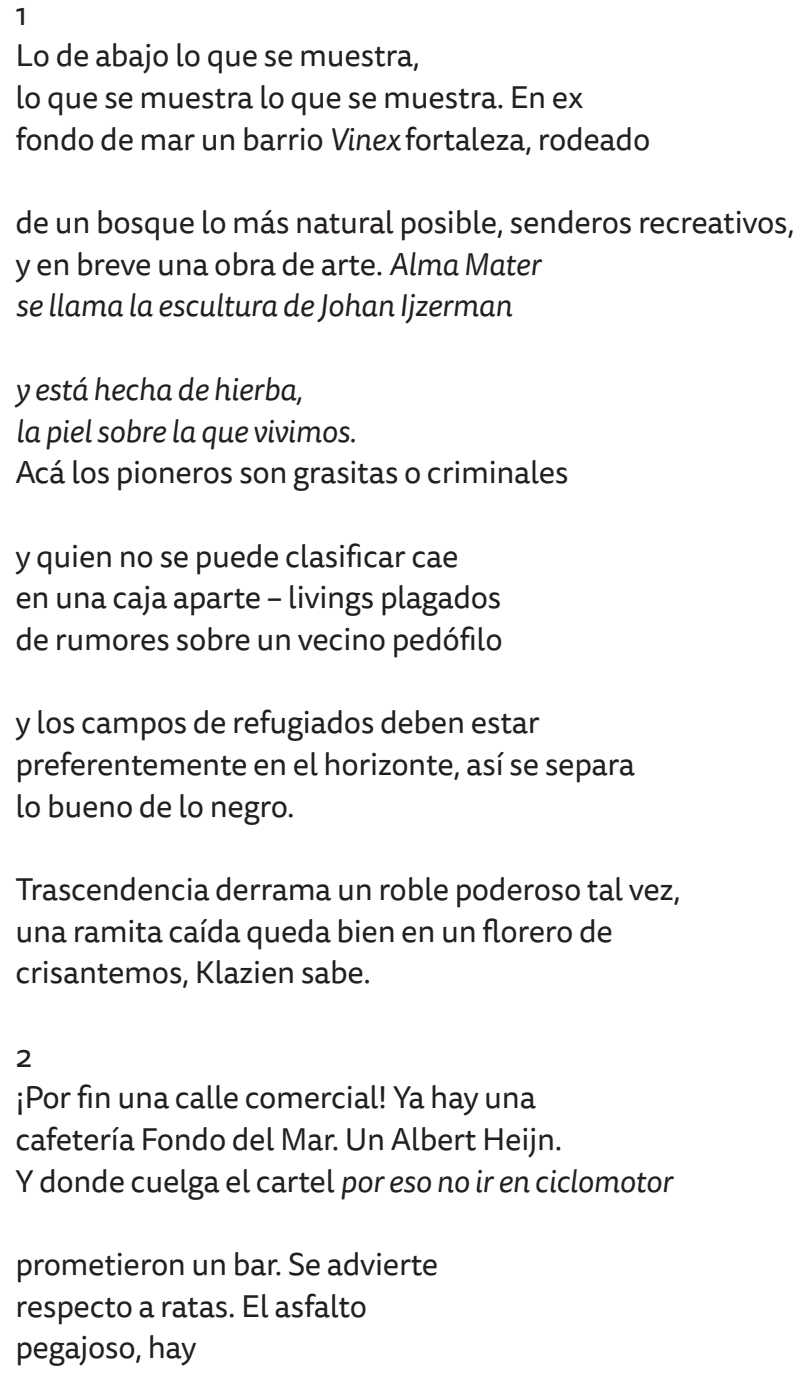

Trascendencia derrama un roble poderoso tal vez, una ramita caída queda bien en un florero de crisantemos, Klazien sabe.

2

¡Por fin una calle comercial! Ya hay una cafetería Fondo del Mar. Un Albert Heijn.

$\mathrm{Y}$ donde cuelga el cartel por eso no ir en ciclomotor

prometieron un bar. Se advierte

respecto a ratas. El asfalto

pegajoso, hay 


\author{
en la calle comercial \\ un ciclomotor \\ en llamas. \\ Lo de abajo \\ lo que se muestra, lo que se muestra \\ lo que se muestra. \\ 3 \\ El dueño de la cafetería tiene aura. \\ Atrae clientes automáticamente. \\ Le sirve a dos Lolitas somalíes,
}

con demanda de asilo rechazada, crema helada guiñando el ojo. Un pavimentador traga y traga sonrojándose mientras mira a escondidas.

Un policía da noticias locales orgulloso: "el exnovio de los restos mortales ha confesado".

Una pareja revieja junto a la mesita de plástico lila,

Frits con su cabeza grotesca, amable, creador de mariposas de madera, y Wilma de hobby granjera en otra vida chupa algo chochea "Frits,

Frits, lo que anoche te había olvidado cuando fui a hacer pis vi en esa luz lunar tan rara no te parece

una bestia de venado en nuestro jardín el mastodonte bebía lo más campante de nuestra fuente así nomás Frits..."

4

Hay que aprovechar el buen tiempo. Infinito.

Lo de abajo es lo que se muestra,

lo que se muestra lo que se muestra.

Wilma y Frits, en un presente eterno esperando el autobús en dirección a Cantemos Todos Bach Tarde de Verano.

Infinito lo que se muestra.

Buen tiempo lo que se muestra.

Lo de abajo lo que se muestra.

Y a los piques de vuelta para casa: gato querido viejo podrido se está muriendo siempre. 


\section{Mustafa Stitou y Varkensroze ansichten (Postales cerdo-rosadas) ${ }^{1}$}

Mustafa Stitou nació en Marruecos en 1974. El mismo año migró con su familia a los Países Bajos. Se establecieron en Lelystad, escenario del poema, una ciudad de unos 77.000 habitantes, construida en tierra ganada al mar. Stitou se licenció de filósofo con un trabajo sobre lo sublime en el arte (Andriessen, 2006: s/p.). En 2018 recibió el premio Roland A. Holst por su obra poética, que, según el jurado, puede parecer modesta (cuatro títulos), pero es original en las letras neerlandesas por su compromiso, ironía, humor y seriedad ("Oeuvre prijs voor Mustafa Stitou”, 02-05-2018: s/p.). Desde su debut, Mijn vormen (Mis formas, 1994), fue premiado y reconocido por colegas y críticos. Mijn gedichten (Mis poemas, 1998), Varkensroze ansichten (Postales cerdo-rosadas, 2003a) y Tempel (Templo, 2013) son sus otros poemarios.

De ahora en más, usaré las traducciones de títulos y poema al español, refiriéndome al texto original en los momentos en que esto facilite o aclare el trabajo. Antes que nada situaré "La piel sobre la que vivimos" en la estructura del libro, reproduciendo los títulos y subtítulos con sus traducciones correspondientes.

Título: Varkensroze ansichten (Postales cerdo-rosadas). Subtítulo: Gedichten (Poemas).

Partes que forman el libro: "Het zingen vergaat je" [Olvidaste el cantar], "Ansichten" [Postales, aquí se incluye "La piel sobre la que vivimos"], "Avondlandse anekdoten, openbaringen" [Anécdotas occidentales (avondlandse=de la tierra donde se pone el sol), revelaciones], "Affirmaties" [Afirmaciones].

Al final del libro (83-84) hay “aantekeningen" (notas), necesarias porque aclaran las fuentes periodísticas, literarias y científicas de los poemas, lo que permite desplazar la lectura, expandirla. También figuran en este apartado las dedicatorias a otros poetas y a su "muzemaatje" (musa y compañera) de poemas particulares y los créditos de textos ya publicados con anterioridad.

Los poemas son lúcidos en sus retratos de una Holanda posterior al 09-11-2001, sin caer en obviedades, e incluso, se han anticipado a los discursos de la derecha alternativa (altright), haciendo más explícito lo que ahora líderes políticos dicen sin disimulos. El poema dice "Lo que está abajo es lo que se muestra" porque todavía a fines de los noventa en Holanda regía ese pudor retórico que llamamos corrección política. De todas formas, en el lugar donde transcurre "La piel sobre la que vivimos", el racismo es una presencia innominada que está ahí, como ya comprobaremos, en forma estructural, o sea no como una característica de casos y personas individuales sino como piedra angular de la vida social y del estado.

A modo de ejemplo, paso a enumerar una selección de momentos del libro, sin pretender definir ni agotar los fragmentos mencionados, que son mucho más

1 Agradezco a la Dr. Maria Salete Borba (Unicentro-PR-Brasil) por la ayuda desinteresada y al Dr. Gabriel Inzaurralde (Universidad de Leiden) por la disponibilidad para leer este artículo y las sugerencias. 
sutiles y merecen ser leídos en su totalidad. En un bar de un hotel de Ardèche, la simple anécdota de un yo lírico que se quiere tomar un cafecito expone conflictos raciales poscoloniales (7-10). En otro poema (39), la diosita rubia es inalcanzable para, probablemente, el mismo yo lírico. El tatuaje que dice "Anton" muestra que ella ya tiene dueño. El poema basado en los diarios de Charles Darwin, con el significativo título de "Shakespeare, misselijkmakend of omtrent onze vader, details" (Shakespeare, nauseabundo o respecto al padre nuestro, detalles) mezcla la banalidad de la vida cotidiana, y la nueva "religión" que parece basada en la razón pero que es una justificación del racismo y de la dominación colonial (5259). Otro poema se llama "Avondland" (60-62), mucho antes que el político de la derecha alternativa neerlandesa, Thierry Baudet, rescatara el término de Oswald Spengler para su polémico discurso de festejo por los resultados positivos de su partido en las elecciones de 20 de marzo de $2019 .{ }^{2}$

Volviendo a los poemas, Stitou explica su método de trabajo de la siguiente manera:

Escribir poesía es una aventura para mí. No planeo con antelación. Pongo sobre la mesa atributos disímiles y los voy moviendo. Después amaso una anécdota alrededor que cuento como si estuviese en un bar. Me entusiasma, por ejemplo, escribir un poema con las palabras once de septiembre, árabe, diosita rubio-dorada y NSB [Nationaal-Socialistische Beweging, movimiento nacionalsocialista]. Así surgió "Anton", un poema conceptual anecdótico. Todas esas palabras traen significados cargados, diversos, que coloco en una situación cotidiana (Andriessen, 2006: s/p).

Además de buscar anécdotas y ciertas palabras de la vida diaria, Stitou usa el readymade, citando más allá de los libros (otros poetas, autobiografía de Darwin), por ejemplo a los periódicos barriales gratuitos, o incluso notas más banales, como las que le deja su vecina: "descongelé la heladera; el paquete de manteca ahora está en mi casa; tiene mucho hielo invisible" (Coumans, 2013: 40-41). Son verdaderos objets trouvés discursivos que provocan tanto el reconocimiento como el extrañamiento. Deconstruyen relaciones de poder y diferencias, por el simple hecho de denunciar que "lo que está abajo" es en realidad “lo que se muestra", o sea, evidente. Intentaré describir este procedimiento y sus efectos en el análisis.

\section{"La piel sobre la que vivimos"}

El poema ha impactado a los críticos y en la bibliografía sobre la obra de Stitou se encuentran diversos artículos que analizan al menos un fragmento. ${ }^{3}$ He tomado gran parte de estos textos en mi bibliografía, a veces como información

2 Su retórica dio mucho que hablar en los Países Bajos, no solo desde el punto de vista ideológico. La terminología culta y las citas literarias para unos pocos elegidos son un cambio en cómo se presenta la derecha y la islamofobia, que antes, con Geert Wilders, tenía el lenguaje del hombre común. De esta manera, Baudet retoma el dandismo de Pim Fortuyn (antecesor de Wilders y Baudet, ferviente anti-islamista, asesinado en el 2002 por un militante medioambiental). Veáse https://www.trouw.nl/religie-en-filosofie/historicus-frits-boterman-baudet-positioneert-zich-als-eenzame-profeet- a69dd8d6/ para uno de los tantos análisis del sorprendente discurso.

3 Parte de los artículos figuran en https://www.dbnl.org/auteurs/auteur.php?id=stitoo1. 
suplementaria, otras como apoyo a mis propias observaciones pero también como contrapunto, ya que no siempre comparto las hipótesis de los autores.

En el título he optado por la palabra piel en lugar de cáscara o corteza para la traducción de schil. Además de la similitud formal (una sílaba, la "i", la "l" final), me pareció más adecuado usar un término que refiere también a la epidermis, en un volumen donde el racismo tiene un lugar tan importante. El poema está conformado por cuatro partes y ya, desde la primera estrofa, se nos presenta el leitmotiv, "Lo de abajo es lo que se muestra," que se repetirá con variaciones tres veces más, al final de la segunda parte, en el segundo y tercer verso del cuarto segmento y en la anteúltima estrofa. Sugiere algo latente que devendrá en amenaza, al igual que, en las películas de terror, la musiquita nos anticipa la tragedia.

Al finalizar la primera estrofa se sitúa el poema en un barrio Vinex, construido en tierra ganada al mar. El neologismo del original, vinexvestiging, literalmente fortaleza vinex, está basado en la palabra Vinex-wijk (barrio vinex), como se denomina a los suburbios de los años ochenta y noventa que, en su mayoría, surgieron a partir del Vinex, abreviatura de Vierde Nota Ruimtelijke Ordening Extra, plan nacional neerlandés de ordenación territorial. ${ }^{4}$ Con fortaleza se expresa la sensación de encierro y poco verde que estos barrios padecen y se marca la poca naturalidad del bosque de la estrofa siguiente. En cursiva el objet trouvé, la descripción de la obra de arte de Johan Ijzerman, extraída de un folleto de una actividad cultural realizada en 2000 en Lelystad. ${ }^{5}$ La explicación de la escultura Alma Mater ya no deja lugar a dudas del sitio geográfico donde transcurre el poema. Lelystad es una localidad que empieza a construirse en 1967 sobre terreno ganado al mar. Por eso sus habitantes son pioneros que vienen a poblar tierras nuevas. Pero la utopía es distópica porque los pioneros son grasitas o criminales, klootjes of crimineel. Klootjes se refiere a white trash, un término denigrante pero que a la vez produce cierta lástima, por las condiciones deplorables en las que estas personas se encuentran. Por eso opté por grasitas a pesar de que los prejuicios racistas de muchos klootjes no estén reflejados en dicho término. ${ }^{6}$

Las dos próximas estrofas marcan la temática del poema, la clasificación compulsiva, y el vecino pedófilo que no puede estar en el campo de refugiados con lo negro, que por la construcción de los versos, "[...] así se separa/ lo bueno de lo negro", tendemos a leer como "malo". Lo bueno es lo blanco y lo malo es lo negro. "Los campos de refugiados [...] en el horizonte" es una referencia al centro Luttelgeest, a unos cuarenta kilómetros de Lelystad. ¿ ¿Habrá algo más allá de lo que se muestra? El roble ¿es trascendente? Aquí hay dos intertextos: el famoso poema de los crisantemos de Hans Faverey ("Los crisantemos,/ que están en el

4 Nederlands Spaans van Dale Grootwoordenboek, Utrecht/Antwerpen, 2003, p. 1219.

5 Véase https://www.flevokunst.nl/sites/default/files/projects/174/322000_sunsation.pdf.

6 Además del folleto de Sunsation (veáse nota 4 y bibliografía) que contiene información textual y fotográfica de la escultura Alma Mater, se puede ver el sitio del artista: http://www.yzerman.nl/images/foto/almamater. htm, que además contiene una versión anterior de "La piel sobre la que vivimos", que no por nada se titula "Subtopia".

7 Información al respecto en https://www.coa.nl/nl/zoek-locatie/luttelgeest . 
florero sobre la mesa/ junto a la ventana..."8) y Klazien, personaje que ya había figurado en Mis poemas (Rovers, 2004: 148). Banalidad y trascendencia están aquí tan ligadas que no se pueden separar, no se pueden poner en cajas aparte.

En el segundo segmento, el alivio respecto a la llegada del progreso (la calle comercial, el supermercado Albert Heijn y la cafetería), es, sin duda, irónico. El nombre original de la cafetería es Tumba de Marinero (Zeemansgraf) pero, siendo el fondo del mar el cementerio del marino por excelencia y por el tono demasiado tétrico en español de esta expresión muy usual en neerlandés, opté por desviar levemente el significado, a pesar de que el aire slauerhoffiano del término debería apelarme. ${ }^{9}$ Irónicamente la tumba es el fondo del mar que es el pólder donde se erige el barrio Vinex y es imposible darle vida a tanta muerte, a este cemento planificado. El también típico cartel por eso no ir en ciclomotor, es un signo más de la sobredosis reglamentaria del Estado. Estos textos cuelgan bajo carteles de tránsito que indican "sendero de bicicletas" para dejar muy claro que las motonetas están prohibidas, en una sociedad que separa lo bueno de lo negro y que del fondo del mar construye un barrio donde todo está en su lugar. Pero el progreso es relativo, el bar que prometieron no ha llegado, hay ratas y la amenaza se hace táctil (...El asfalto/pegajoso). No cabe lugar a dudas, el peligro está allí: el ciclomotor en llamas y la última estrofa de esta parte, el leitmotiv. La violencia es evidente.

La tercera parte nos muestra de cerca a los personajes del barrio. El dueño de la cafetería tiene un aura benjaminiana, un carisma que le proporciona clientela y que explica cómo sobrevive en medio de tal desolación. Las Lolitas somalíes ilegales, también buscándose la vida, y el pavimentador que las mira de reojo son lo negro y lo blanco, ya no tan separado. La declaración rebuscada del policía a los medios locales es un elemento más de esta banalidad que también comparten Frits y Wilma. Los restos mortales, el peligro que corren las clandestinas, el helado, el calor, la mesita de plástico lila: hay amenaza, tristeza pero también cierta ternura del poema hacia sus criaturas suburbanas. La pareja revieja, Frits y Wilma, son los verdaderos pioneros, los que reconstruyeron Holanda después de la segunda guerra mundial. Parecen amables pero se irritan con el ciervo que bebe agua en su jardín; la naturaleza no puede invadir la civilización, tiene que quedarse en la jaula, en el cajón etiquetado.

"Hay que aprovechar el buen tiempo", el comienzo de la última parte, podría ser una frase que dicen Wilma o Frits o cualquier adulto neerlandés "autóctono", que hacen del tomar sol un deber. Es verdad que hay una necesidad corporal de sentir el sol siempre que se presente para todo pueblo que viva en lugares donde por lo general está nublado y hay poca luz. Pero, aquí se trata de una obligación, moet worden benut, debe ser aprovechado. El infinito da una idea de complacencia y bienestar en el día de verano, en “Subtopia”, primera versión de este poema, figura

$8 \mathrm{El}$ original completo está disponible en https://www.dbnl.org/tekst/faveo01chry01_01/fave001chry01_01_0063.php.

9 Een eerlijk zeemansgraf (Una honrada tumba de marino) es el título del poemario que Jan Jacob Slauerhoff (1898-1936) publicó poco antes de su muerte. He publicado con anterioridad sobre dicho escritor neerlandés. 
como una "especie infinita de/ suficiencia", "oneindig soort/ genoegzaamheid" (Stitou, 2003b: s/p.). La "suficiencia" en el sentido de "presunción", pero también en el sentido de "autosatisfacción", el consenso holandés, todo está bien, incluso en Lelystad. Volveré sobre esto más adelante. Aquí sí, el leitmotiv se resuelve, se explica: "Lo de abajo es lo que se muestra" (la cursiva es mía). Ya no se trata de una amenaza latente, está a la vista.

En las próximas estrofas vemos escenas en la vida autocomplaciente de Wilma y Frits: el coro, el gato viejo. Es bastante patético, el autobús y cantar Bach parecen ser los pocos contactos que tienen con el mundo, considerando la poca frecuencia de los autobuses en estos parajes, una vez por hora en horarios diurnos, o incluso menos, es lo normal. La estrofa que une el autobús con el gato repite el leitmotiv, lo que se muestra es el buen tiempo de verano y lo infinito. Hay un vacío en el paisaje casi pampeano del pólder, la banalidad de que todo está bien, y, al mismo tiempo, la idea de jaula y de encierro en ese orden de cosas, en el Vinex. El gatito que no se muere es un final algo abrupto y cruel, ya que Wilma y Frits también van a morir. ¿Y qué será de Lelystad? ¿Una Lolita somalí seducirá al pavimentador y tendrán hijos mezcla de lo bueno con lo negro? Eso podría ser, aunque la compartimentación espiritual sea difícil de superar. Se ve un pueblo pacífico pero, en realidad, lo que se muestra es lo que está abajo: violencia, opresión y amenaza. El infinito del suburbio está basado en que puede clasificar en cajas casi todo lo que está vivo. Esta conclusión de mi interpretación sería, tal vez, algo especulativa, pero lo que me interesa es marcar algunos puntos por los que el poema es muy sugerente y actual.

El análisis de Joosten y Vaessens (2005) es acertado respecto a la crítica de Stitou a la modernidad, a Darwin (el close reading del poema basado en sus diarios es detallado, preciso) y al racismo. Pero los autores se equivocan al decir que el racismo en "La piel sobre la que vivimos" sea el racismo de los klootjes (grasitas) (2005: 148). Ya lo he introducido durante el análisis y lo repito: el racismo es la estructura sobre la que descansa la sociedad neerlandesa, la piel sobre la que vivimos. Es lo que se ve, la separación de lo bueno de lo negro, los campos de refugiados, la urbanización y los jardincitos en los que no puede entrar un venado porque los destroza. Lo que dice el poema es que el racismo es estructural, más allá de lo que los klootjes piensen o hagan, o Wilma o Frits. Lo que sí comparten todos los personajes del barrio (incluyendo a las Lolitas somalíes) es la suficiencia, la genoegzaamheid, el consenso respecto a que esta situación es el mejor mundo posible, a pesar de las ratas y del ciclomotor en llamas.

\section{Compromiso como amor político}

Joosten y Vaessens se refieren al compromiso de Stitou, su engagement. El compromiso es algo que solo puede tenerse desde adentro, lo que Sandoval denomina "amor", una de las tecnologías de las subalternas, del feminismo otro (2004: 85-86). Pero antes de aclarar el compromiso como amor en Stitou, daré datos 
concretos para justificar por qué me parece una aberración que Joosten y Vaessens afirmen que Stitou “eligió" la tradición poética neerlandesa para ejercer la poesía (130).

Es evidente que Stitou no eligió nada, lo trajeron a los Países Bajos antes de que cumpliera un año y su educación transcurrió en la escuela pública neerlandesa y la Universidad de Ámsterdam. Es probable que haya escuchado otra lengua en casa, pero el idioma de la vida cotidiana en Holanda es el neerlandés. Nijborg y Laroui sugieren que para los escritores neerlandeses de padres marroquíes, volcarse a hacer literatura en neerlandés es una solución bastante práctica, por el hecho de las particularidades de las lenguas marroquíes (2013:235-290). Simplificando mucho la explicación lingüística, el marroquí es una lengua solo hablada, el árabe es el idioma escrito (pero sagrado) y la mayoría de los inmigrantes que están en Holanda son bereberes cuyas lenguas casi no han sido escritas hasta la fundación del Instituto Real de la Cultura Amazigh en 2001. Pero estas razones son superfluas. Hay casos de escritores que emigran y cambian el idioma en el que escriben, opción que jamás tuvieron Stitou ni otros poetas y prosistas neerlandeses de origen marroquí, por el simple hecho de que, como escritores, nacieron en la cultura neerlandesa. Además, como muy bien lo demuestra T’Sjoen, los méritos de Stitou son literarios, su diferencia es la que le corresponde a la inevitable multiplicidad que habitamos, no un pretendido origen exótico. Es absolutamente irrelevante "exotizarlo" (2013:279-281), aunque las editoriales hayan utilizado la etiqueta "marroquí" por razones comerciales.

Lejos está el libro Postales cerdo-rosadas de pretender ser marroquí, ni menos aún halal, la tapa es una piel de cerdo, bestia impura para la religión musulmana, y también para la hebrea. Es crítico hacia la sociedad holandesa en su conjunto, incluyendo a sus padres, que forman parte de ella, y a sí mismo. No toma distancia, critica porque ama. Extraigo el concepto de amor que aquí utilizo, del intento que hace Sandoval de sistematizar la tecnología de las oprimidas. Esta es una metodología que reúne la tecnología de lectura de signos, lo que se muestra, separándolos de su significado dominante, la deconstrucción que realiza el poema, apropiándose de las formas hegemónicas y mostrando así que el consenso en Lelystad es una utopía. Aunque esté abajo, en la fortaleza Vinex, el conflicto sigue latente. Esta es una red poética y política que se hace desde un compromiso amoroso y la distancia, el cinismo ocasional del autor es una expresión de que le importa.

El poema encarna perfectamente la política según Rancière (1996), el "visibilizar lo invisible", que se podría equiparar a la metodología de apropiación de las formas hegemónicas de Sandoval para mostrar lo otro, "tomar las palabras de los demás para decir que dice una cosa completamente distinta" (Rancière, 1996: 10). El ya clásico El desacuerdo de Rancière tiene muchos puntos de contacto con el poema, casi parece el programa seguido por Stitou. La policía es la organización impecable del Vínex, del pólder, "el orden de lo visible" (43-44). La política es lo que eclosiona cuando la "parte de los que no tienen parte" (25), los que están abajo aparecen en la poesía comprometida. Los klootjes grasitas, las 
somalíes, Frits, Wilma, las criaturas olvidadas de Lelystad, un lugar recóndito de los Países Bajos, un lugar que no tiene lugar, en el fondo del mar, donde no llegan los turistas, Stitou le devuelve a Lelystad su belleza en su fealdad y lo hace poema. Les "da lugar a los que no tienen lugar" (115). Y también denuncia que esa cárcel, ese pólder, ese invisibilizar, es consensual. Europa es la piel sobre la que vivimos. Es la posdemocracia que liquidó el litigio y despolitizó las relaciones sociales (129). Cada uno está en su lugar y se ocupa de sus propios asuntos (134), cada uno tiene su propia caja. Rancière explica el proceso de exclusión de los inmigrantes (145-152) que Stitou presenta en el poema. La exclusión de los que están en los campos de refugiados es el otro nombre del consenso; el inmigrante de hoy perdió su identidad de obrero o proletario y solo conserva su raza, su piel. Y así se lo separa de los klootjes, los criminales, la basura blanca. Ya no se pueden contar como incontados. Las somalíes son criminales, más que los holandeses criminales, porque son clandestinas, ilegales. A los klootjes la ley los ampara, entraron en la caja. Tal vez sí ellas tengan más suerte que otros inmigrantes, por lo menos les dan helado y miradas avergonzadas.

Dilucidar cómo Stitou logra que su texto resista, dialogue e incorpore el mundo otro, no es sencillo. Tuve que traducir el poema y explicar referencias. De todas formas estoy convencida de que mi procedimiento de análisis, la mención de la crítica neerlandesa y luego el abrir "La piel sobre la que vivimos" a textos más generales de filosofía y política, lo ha acercado con toda su riqueza, aunque el lector no esté inmerso en la lengua ni en la cultura neerlandesas. Y esto es mérito de la poesía de Stitou, que resiste e incorpora, muestra, ese mundo otro, lo que está abajo. 


\section{Bibliografía}

"Andriessen, M. (2006). "Mustafa Stitou". En el sitio web de Poetry International: https://www.poetryinternational.org/pi/site/poet/item/4030 (consulta: 20/10/2020).

" Coumans, K. (2013). "Vier dichters in een busje. Over eigenheid en verwantschappen in het werk van Eva Gerlach, Tonnus Oosterhoff, Mustafa Stitou en Menno Wigman". En De Revisor. Halfjaarboek voor nieuwe literatuur 06-07. En la Biblioteca Digital de las Letras Neerlandesas: <https://www.dbnl.org/tekst/_rev002201301_01/_ rev002201301_01_0023.php> (consulta: 20/10/2020).

"Joosten, J. у T. Vaessens (2005). "Identiteit, evolutie en engagement. Moderniteitskritiek in de poëzie van Mustafa Stitou". En Nederlandse Letterkunde. Jaargang 10. En la Biblioteca Digital de las Letras Neerlandesas: <https://www. dbnl.org/tekst/_ned021200501_01/_ned021200501_01_0012.php> (consulta: 20/10/2020). [Los mismos autores han publicado un artículo mucho más breve y en francés con la misma temática, en: <https://www.dbnl.org/tekst/_ sep001200501_01/_sep001200501_01_0033.php>]

"Nijborg, M. y F. Laroui (2013). "The emergence of a Dutch-Moroccan literature: an institutional and linguistic explanation". En Behschnitt, W.; S. De Mul y L. Minnaard (ed.), Literature, Language and Multiculturalism in Scandinavia and the Low Countries. Amsterdam - New York: Rodopi.

"Oeuvre prijs voor Mustafa Stitou (02-05-2018). En el sitio web de la Fundación neerlandesa de letras: <http://www.letterenfonds.nl/nl/entry/1981/oeuvreprijsvoor-mustafa-stitou $>$ (consulta: 20/10/2020).

"Rancière, J. (1996). El desacuerdo. Política y filosofía. Trad. de Horacio Pons. Buenos Aires: Nueva Visión.

"Rovers, D. (2004). "Wie is er bang voor metafysica?" En Yang. Jaargang 40. En la Biblioteca Digital de las Letras Neerlandesas: <https://www.dbnl.org/tekst/_ yano01200401_01/_yano01200401_01_0016.php> (consulta: 20/10/2020).

"Sandoval, C. (2004). "Nueva ciencias. Feminismo cyborg y metodología de los oprimidos". En Otras inapropiables. Feminismos desde las fronteras. Trad. de María Serrano Gimenez, Rocio Macho Ronco, Hugo Romero Fernández Sancho y Álvaro Salcedo Rufo. Madrid: Traficantes de Sueños.

"Stitou, M. (2003a) Varkensroze ansichten. Gedichten. Amsterdam: De Bezige Bij.

"Stitou, M. (2003b). Subtopia. En sitio web del artista J. ljzerman: <http://www. yzerman.nl/images/foto/almamater.htm> (consulta: 20/10/2020).

"Sunsation 2000. Festival de la asociación de artistas de la provincia de Flevoland. Folleto disponible en internet: <https://www.flevokunst.nl/sites/default/files/ projects/174/322000_sunsation.pdf> (consulta: 20/10/2020).

" T' Sjoen, Y. (2013). "About the (non-)existence of 'migrant literature' in The Netherlands: or, why Mustafa Stitou is a Dutch author". En Behschnitt, W.; S. De Mul y L. Minnaard (ed.), Literature, Language and Multiculturalism in Scandinavia and the Low Countries. Amsterdam - New York: Rodopi. 


\section{Breve reportaje}

Mustafa Stitou accedió a responder por correo electrónico las siguientes preguntas

P: ¿Ha leído los artículos de Joosten y Vaessens (2005, en Nederlandse Letterkunde y Septentrion) donde dice que usted "elige" la tradición neerlandesa en literatura? En mi opinión usted no eligió porque como bebé no podía tomar la decisión de emigrar y criarse en Holanda. ¿Qué opina al respecto? ¿Ha tenido la posibilidad de elegir?

Stitou: He leído el artículo por encima, de eso ya hace unos años, por lo que no lo recuerdo del todo. Yo tenía dos meses cuando vine a los Países Bajos. Es, entonces, algo no elegido por mí. Pero posiblemente ellos quieran decir que, como poeta (adulto), elijo posicionarme dentro de la tradición de la poesía neerlandesa. Y, esto, me parece que es correcto. Me veo como poeta neerlandés (de origen marroquí). Porque escribo en neerlandés (no podría escribir en otro idioma) y formo parte de la comunidad de poetas neerlandeses. Pero, claro, este tipo de descripciones son superficiales. En primer lugar soy poeta y mi identidad como poeta es algo que va más allá de la nacionalidad.

P: "La piel sobre la que vivimos" y muchos poemas de Postales cerdo-rosadas me resultan proféticos. "Lo de abajo es lo que se muestra", la cuestión racial subterránea pero visible. Incluso literalmente, como si Baudet lo hubiera leído a usted y no solo a Menno Wigman (a quien ha citado en varias ocasiones a pesar del descontento de sus herederos). ¿Es esta una razón para no publicar más?

Stitou: Ciertos acontecimientos y tendencias político-sociales me pueden, como a muchos, preocupar, pero el hecho de que después de mi último libro (Tempel, 2013) no haya vuelto a publicar, es independiente de ello. 